Review Article

\title{
The Practical Influence of Climate Change on the Performance of Road Stormwater Drainage Infrastructure
}

\author{
Mohammed Saleh Al-Ghadi $\mathbb{D}^{1},{ }^{1}$ Wan Hanna Melini Wan Mohtar ${ }^{(D)}{ }^{1}$ \\ Siti Fatin Mohd Razali $\left(\mathbb{D},{ }^{1}\right.$ and Ahmed El-Shafie $\mathbb{1}^{2}$ \\ ${ }^{1}$ Department of Civil and Structural Engineering, Faculty of Engineering and Built Environment, \\ Universiti Kebangsaan Malaysia, Bangi 43600, Selangor, Malaysia \\ ${ }^{2}$ Department of Civil Engineering, Faculty of Engineering, University of Malaya, Kuala Lumpur 50603, Malaysia
}

Correspondence should be addressed to Mohammed Saleh Al-Ghadi; msalghadi@gmail.com and Wan Hanna Melini Wan Mohtar; hanna@ukm.edu.my

Received 28 June 2020; Accepted 14 October 2020; Published 2 November 2020

Academic Editor: Bhimappa Suresha

Copyright (c) 2020 Mohammed Saleh Al-Ghadi et al. This is an open access article distributed under the Creative Commons Attribution License, which permits unrestricted use, distribution, and reproduction in any medium, provided the original work is properly cited.

\begin{abstract}
The atmospheric temperature globally has risen during the last few centuries, causing global warming and climate dynamics. The impact of global warming has caused environmental effects that include increased rainfall intensity, which is recognised as the leading cause of flooding, and destruction and devastation to the surrounding environment, infrastructure, and human life. Road stormwater drainage systems are used for removing and controlling excess runoff water to the right way. However, regardless of enhanced technologies, the reliability of drainage system schemes remains a major undertaking for water and hydraulic engineers alike. In this study, a thorough evaluation of the methods employed in previous studies and research on rainfall forecasting models was undertaken. Further to that, the effect resulting from climate change on structures of drainage infrastructure is considered in addition to the methods to enhance drainage system challenges with recent models developed for advanced drainage and waterway requirements that need to be designed in consideration of climate change.
\end{abstract}

\section{Introduction}

There is no doubt that temperatures on average of the past few years have risen increasing the need to recognise and take action on a global scale to prevent changes from continuing, at worse escalating, impacting our environment. The World Meteorological Organisation (WMO) and the Intergovernmental Panel on Climate Change [1] confirmed these climate change modifications, while the effects of climate change include increased rainfall intensity, which is recognised as the leading cause of flooding [2,3]. A number of investigations have been undertaken in supporting the future climate change hypothesis and conditions across different areas. Rising intensity and unpredictability that influence hydrological reactions towards global warming, thus impacting our environment, continue to impact the changes in rainfall conditions and intensity going forward
$[4,5]$. When perceived as an impartial challenge, climate change is nowadays viewed as a perplexing warning, which can interact with other ecological and societal forces in moderating the change results [6].

Furthermore, climate change also affects the quantity of runoff that reaches urban highways and drainage systems, thus conflicting with current drainage system layouts and runoff that causes unreliable containment [7]. Floods constitute the leading threat to highways, and many researchers believe that, due to inadequate drainage, this is a major cause of discomfort to pavements and subsequent destruction [8]. According to [9], eighty percent of road issues that occur are due to the existence of water and poor drainage in and around roads. Extreme water conditions that flow in and across pavement layers like foundations, subgrade, and subbase soils can contribute towards functional and structural road failure if countermeasures are 
not taken. Another research [10] examined many innovations introduced around the world to adapt with and protect transport infrastructures against the impact of climate change. Three key threats to climate change have been observed: air temperature fluctuations and extremes, water bombs, and increasing sea levels, and the findings of the study suggest that continuing climate change would intensify its effect on transport infrastructure and expose people to unacceptable risks. Accordingly, preventive and protective measures of the frequent floods must be taken more frequently for collective safety.

Furthermore, floods and high-water flows have a significant impact on the efficiency of drainage systems, as the anticipated trend of flood events could affect the quantity and variety of events, namely, road closures, flooded and submerged bridge supports, and roads completely washed away [11]. The effects caused by flooding can be substantial regarding road drainage following the event since it can impact important infrastructure that needs to be in place, thereby having a prolonged effect, if maintenance and repairs are not swiftly carried out. These events also need to be addressed with respect to road infrastructure planning in future [12]. Notable effects of these incidences can result in stress and exhaustion of those impacted and lost working hours of those travelling along these roads, resulting in longer travelling time, traffic congestion, road networks disrupted, turning points obstructed, bridges closed, and major destruction of highways and other areas. Other impacts may also include the recovery of lost property, further flooding, and needed infrastructure to cope with future incidents. It only takes one to two hours for flash flooding to revert to normal conditions and discharge flows $[13,14]$. A short-term (less than six hours) flash flood resulting from a substantive rainstorm can rapidly raise the water level in rivers and streams. Substantive rainfall incidences in Malaysia are often connected to ecological catastrophe-like flash flooding during monsoon seasons and landslides [15-17]. The extent of interactions of differing road networks and other aspects can be assessed to gauge the effect of flooding. The flood effect can be modelled and visualised by assessing the probability of contact [18].

Many scientists have explicitly researched the impact of global warming leading towards the tail end of the twentyfirst century and the resilience of present drainage systems $[19,20]$. Researchers have recognised several problems related to the failure of the drainage infrastructure scheme and have attempted to resolve these potential failures. The study in [21] used the model of runoff generation to study urban stormwater drainage systems having a low impact. Another research [3] examined the effect on metropolitan drainage systems due to climate change and urbanisation. Recent advancements in maintaining drainage systems through various disciplinary areas, such as engineering and science, have been investigated. Likewise, the conceptual knowledge of drainage systems and issues to adapt with the changing conditions were disclosed in the work of [20], through understanding the concept of the problems connected with urban drainage systems specifically, but also regarding examining various alternatives to adaptation, the study in [22] recently explored present solutions to downscaling the projection of rainfall. One of the many components arising from climate change is the change in extreme occurrences induced by rain. Therefore, to define its effect, it is essential to evaluate extreme occurrences.

Overall, the inability to recognise the boundaries of climate change predictions and to inform policymakers and those making decisions has led to a suboptimal proliferation of data that could lead to maladaptation [23]. Likewise, the utilisation of resources needed to address urgent, if not sensitive, climate issues in developing nations are imperative as with the constraints associated with the predictions of climate change [24]. For the nonspecialist, the implications of these constraints on the practical development of solutions and decision-making have not been established. Accordingly, in this study, the assessment of the methods adopted in the literature on the models of rainfall projection is reviewed. Furthermore, the effect of climate change on the intensity of drainage infrastructure structures, including quantitative and qualitative management, is considered in addition to the methods to improve drainage system challenges and problems with drainage, as these can be reported in numerous ways, such as via reports from locals, incident and accident information, and field analysis [25].

\section{Projections of Climate Change}

Water resource management (WRM) and those making decisions need to acquire precise local and global environmental data in order to consider the changes brought about through climate change and related impacts [26]. Present climate prediction protocols are founded on the numerical simulation technique of the global circulation model (GCM). Climate change projections, which were initially created to advice policymakers on conservatory experience approaches, are nowadays needed to notify of highly contained and intricate choices in their adoption [27]. The GCM simulates the earth's environment that includes interactions associated with oceans, biotic processes, and the atmosphere. The simulation model is focused on providing reliable and realistic information for semiglobal and global areas and predicting greenhouse gas emissions as well as the outcomes relevant to climate change. Fluctuations in the grid size between 100 and 500 kilometres and the same value for simulated grid cells are defined in this model [28]. However, regardless of the attractiveness of GCMs, there are drawbacks regarding the analysis (e.g., modeling weaknesses and incomplete information). Figure 1 illustrates the notion surrounding the process of downscaling, which includes defining all accessible data much better than monthly documents and implementing temporary scales of less than $100 \times 100$ kilometres in space. From reviewing the literature, there are several approaches, dynamic and statistical, that can be adopted.

The regional climate model (RCM) is used to depict downscaling and applies the GCM to provide lateral weather information and deliver practical spatial resolutions within 20 to $50 \mathrm{~km}$, including details such as topography, soil heterogeneity, land-sea comparison, and finer physical 


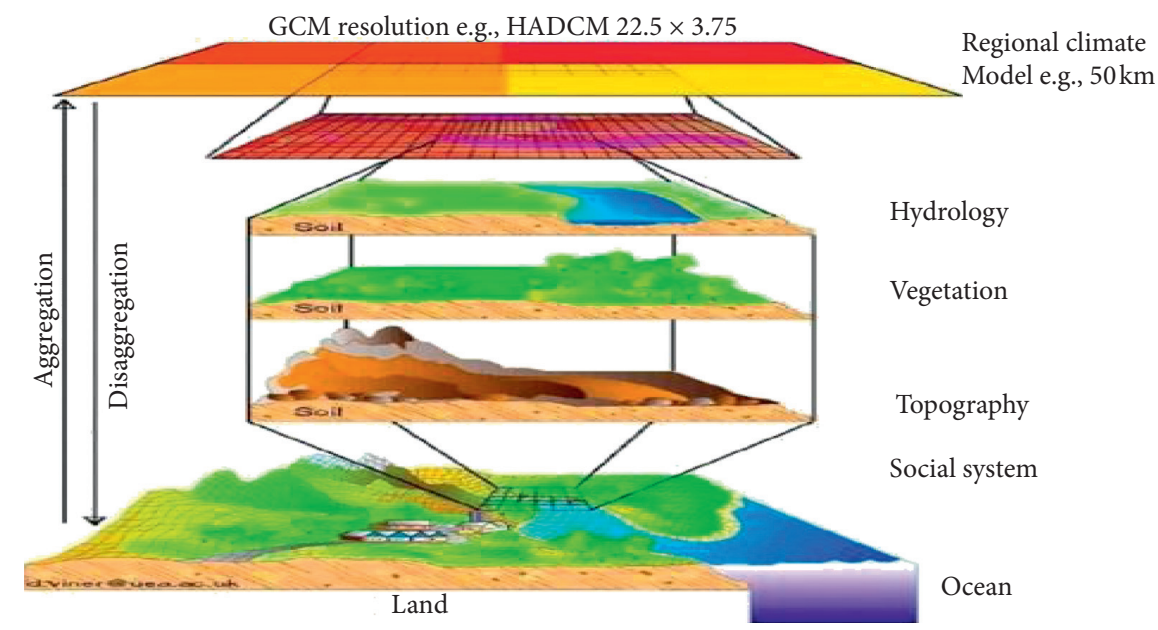

FIgURE 1: The concept of decreasing spatially (redrawn from [29]).

processes. Regardless of its important regional characteristics, the RCM results are frequently subjected to errors or mistakes that require adjustment and further reduction to achieve greater (better) resolution. Moreover, to obtain more precise outcomes between the output of the model and real observations, statistical partial correction is often necessary. The adjustment of the model represents the distribution and statistical information observed.

The second approach, known as quantitative downscaling, on the other hand, is a methodology used to check the experimental relation of both the past and present for local and global climate variables. Future weather variables, in this case, can be applied by establishing and validating this link, using GCM projects to estimate the scale of climate factors in the region. The interpretation of the statistical reduction technique is premised on the basis that there is a link between large-scale and local climate circulation [30]. Statistical downscale modelling produces distinctive hydrological characteristics of a specific station scale that is essential for hydrology research. Moreover, downscaling is used as a tool to apply daily GCM climate variables on a large scale to the local scale [31].

The Intergovernmental Panel on Climate Change [1] has proposed four model classes for pollution: A1, A2, B1, and B2. Examples include an adaptive and direct outline of the future global climate position. Reporting on technological, demographic, economic, and environmental trends is needed so that future greenhouse gas emissions can be represented. The A2 scenario claims elevated emission rates of greenhouse gases, while the B2 scenario reports reduced emission rates and utilised a reviewer for the environmental issues globally and locally [32]. The theories surrounding $\mathrm{A} 1$ and $\mathrm{B} 1$ anticipate global population growth by the midcentury, before declining. However, the economies have changed the scenarios of $\mathrm{A} 1$ and $\mathrm{B} 1$ to concentrate more on the environment. Supplementary data can be discovered in the literature on the situation of the fourth group. Regarding the scenarios for pollution, the scenarios for A2 and B2 indicated an increase in temperature during weather seasons, while predictions for evaporation and precipitation did not rely on extreme weather conditions [1].

Yang et al. [33] reduced multiple atmospheric factors (i.e., precipitation, evaporation, and extreme temperature) acquired from GCM development in South China in order to analyse spatial-temporal shifts using local scales. Here, they used the statistical downscaling model (SDSM) findings due to future climate scenarios of precipitation, evaporation, and day-to-day temperature. The results suggested that the simulation was useful in creating weather, while the efficiency of generating immense precipitation occurrences was reduced compared to the temperature and evaporation parameters. In another study [34], a vibrant model to reduce day-to-day precipitation in the Indian Mahanadi Basin was developed. The model was constructed based on integrating the $K$-nearest neighbour (KNN) and SVM model. Further, the development of a variable performance ensemble structure recognised several possible combinations of model parameters. Accordingly, the findings indicate that simulation of the integration was improved, compared with a single model when obtaining the expected rainfall pattern.

\section{Future Changes in Precipitation, Variability, and Impact on Road Stormwater Drainage}

Over the last five centuries, rainfall changes have been vastly affected by the hydrological system of many rivers with significant impacts on water supplies [35]. The Intergovernmental Panel on Climate Change assessment report [12] shows that vast rainfall globally in future could become more regular and severe. Therefore, the hypothesis of the likelihood of climate change concerning periodic extreme rainfall events is extremely questionable. However, for the present moment, the designed storm model founded on historical data can only be tested, but not relating to the entire life of the drainage system. Moreover, in constructing drainage systems that are efficient, engineers and other practitioners must incorporate climate conditions that reflect the future into their estimates to develop stormwater drainage systems, given the extent of the anticipated discharge is at this 
juncture uncertain. Also, the numerical parameters associated with the hydrological variables will not alter over the long term without the need for profound changes.

Nevertheless, the intensity of rainfall increases in the future will likely be impacted by changes to our climate, thereby resulting in the stationary hypothesis being mistaken. Many simulations depicting climate change on a global scale using RCMs have evaluated extreme rainfall changes in the future. Figure 2 shows the trends of the observed precipitation from 1980 to 2018 . Several studies have examined direct empirical diagnoses, such as extreme seasonal rainfall $[35,36]$. However, it is commonly recognised that, due to rainfall occurrences, worldwide infrastructure will gradually become much worse and weakened. Therefore, accurate data on extreme rainfall occurrences is crucial from a number of perspectives, such as efficient management of water, property protection, and, more importantly, the sustainability of drainage infrastructure systems $[37,38]$. Based on methodologies and data sources considered reliable, precipitation patterns were used to interpret real rainfall information of neighbours using the principle of "return period." The thinking regarding the "average recurrence interval" (ARI) was applied to show flooding events in the future [39]. ARI is able to effectively depict the likelihood regarding the volume and duration of the rainfall event [40].

A rise in rain intensity due to the effects caused by climate change can fluctuate anywhere between $20 \%$ and $80 \%$, although these percentages depend on the region's nature $[38,40]$. For example, this particular problem presented a significant challenge to present road drainage systems, which were originally intended to have a service life of at least 50 years [2]. Drainage systems face capability issues owing to climate change in adapting to current water flows. As such, the future design of drainage systems needs to cater for the intensity and variability of rainfall events in maintaining sufficient drainage due to flooding [41]. Many researchers have noted the concern about the effect of climate change and the influence on current drainage systems. The influence of climate change has been investigated and examined on the likely impact with respect to the performance of urban drainage systems. The researchers documented that, for risks related to flooding, these may surge by about 30 times and that standard engineering processes do not provide safety under these conditions [42].

3.1. Flood Challenges in the Region of Malaysia. Malaysia is situated in a virtually "disaster-free" geologically stable area, except for flooding and disasters caused by humans [43]. The nation is also seen as a stable climate region, distanced south of the main typhoon tracks, even though the tail end of tropical storms sometimes hit the country [44]. Malaysia is regularly plagued by hazards, landslides, disasters, droughts, and flooding caused by people [45]. Likewise, a vast volume of intangible losses, destruction of crops and properties, and diseases are caused each year by floods [46]. The nation has continued to experience adverse climatic and weather events over the last twenty years or so, resulting in significant

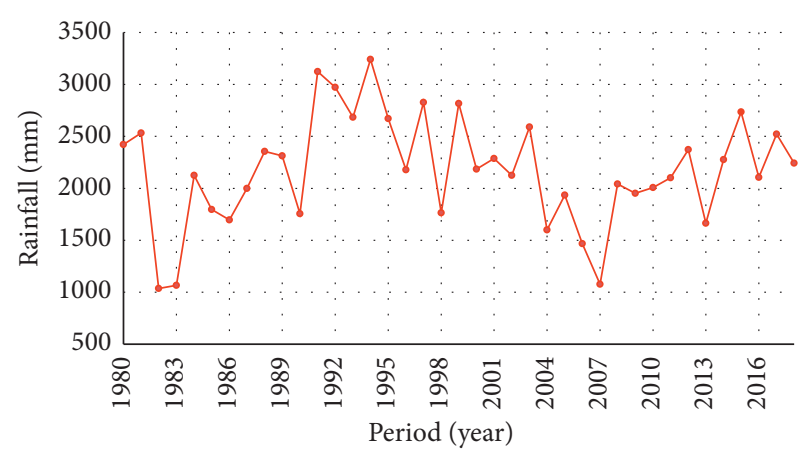

Figure 2: Time series plot of the precipitation trends for state of Selangor, Malaysia.

floods. These floods were predominantly caused by monsoons (resulting in severe damage, including the loss of human life in numerous country regions subjected to intense monsoon storms), which occur each year and vary in the period of the event occurring, location, and intensity [28]. As reported by [47], Director General of the Drainage and Irrigation Department (DID) of Malaysia mentioned that flooding and catastrophes have continually impacted Malaysia, currently and previously, for many decades as a result of wet equatorial climate and seasonal monsoon winds.

DID [48] emphasizes that the present policy requirements and implementation measures to mitigate against floods include the following: (i) measures that address the engineering and socioeconomic environment of structural flood mitigation; (ii) introduction of nonstructural complementary measures; (iii) introduction of nonengineering measures upon which the engineering solution is unavailable; (iv) continuing to strengthen flood prediction and warning systems. Additionally, a range of flood mitigation projects was conducted via the government. However, they were predominantly measures around structural mitigation like river embankments, river canalisation, and multipurpose dam construction. The study in [44] observed that structural measures tend to be preferred, even nowadays, regardless of their inflated costs if compared with nonstructural measures. As such, this has driven an upswing in the allocation of funds towards these types of projects in Malaysia. However, increase in expenditure and funding allocated to these sorts of projects has placed a heavy burden on authorities, and suggestions have been put forward to assess other ways to reduce this burden to cope with disasters caused by flooding. For instance, the present government through the Economic Planning Unit (EPU) under the Prime Minister's Department coordinates all aspects of the country's water resource strategy and planning, framework, implementation, and overall design (together with flood management).

However, given this initiative, the managing and execution of mitigating actions to alleviate the impact of floods have not been maintained. As an industrialised nation, given the country's rapid pace towards political, economic, and cultural change, it is no different from that of the pace of environmental change; both are challenging. These are the 
situations where flood risks might be magnified and mismanaged, albeit other things being equal. These environments (physical and natural) are also evolving along with rising risks, susceptibility, and exposure to flooding resulting in physical systems being changed to accommodate. Other conditions are primarily systemic in nature like ethnic culture, landlessness, occupational mobility, low residential areas, and chronic deprivation, which have led to rising susceptibility to flooding amongst some communities, particularly the elderly. Therefore, to better control and manage the hazards due to flooding, such as human life and other casualties, greater focus must be directed to flood management. Likewise, in a nation that prides itself on reducing poverty and revenue equality, alleviating loss or misfortune due to flooding should be high on the government's agenda. This is because less fortunate people (i.e., low-income households) tend to be more exposed to flooding, and therefore, any protection against flooding and reduction of any loss caused would help to reduce the gap related to the disparity in income amongst the underprivileged and those who are more fortunate [44].

3.2. Frequency of Flooding. Since 1971, most areas within Malaysia have experienced flooding, and responding to this issue, the government established the Natural Disaster Management and Relief Committee (NDMRC), in 1972, to manage operations aimed to alleviate the impact of floods across the district, regional, and state levels to prevent damage caused by flooding including loss of life under Directive No. 20 of the National Security Council (NSC) and operational guidelines [49]. In 2010, the nation was exposed to severe flooding that had severe economic and societal consequences in several states. The mean rainfall in Malaysia tends to be around $2500 \mathrm{~mm}$ each year, which, compared to other countries, the considered is the severest rainfall. Over the years, most Malaysian cities have experienced rapid developments, which have led to a continuous change in the face of urban areas. The rapid development is to reduce the areas of green roof and replace them with roofing and concrete. Rahman et al. [50] stated that the flood phenomenon, also known as the flash flood, can also be referred to as a thoughtful flood, where the water level rises rapidly in short durations but is slow to recede. Flash floods are also characterised by a sudden rising of the river and the rivers leading to sewage and wastewater flow being carried over by the height reading well above the riverbanks. NDMO [51] mentioned that floods are the most significant natural hazard in Malaysia, as stated in [52] statistics; see Figure 3.

\subsection{Current Drainage Design and Need for Modification.} Some of the approaches in constructing road drainage systems fail to cater to the hydrological response surrounding particular landscape and instead view it as a process. As such, this can build insufficient structures as the combination of land cover, and climate change can result in an increased hydrological reaction [2]. Most prevailing drainage models were built under saturated conditions based on moisture flow [53]. However, the saturated flow will

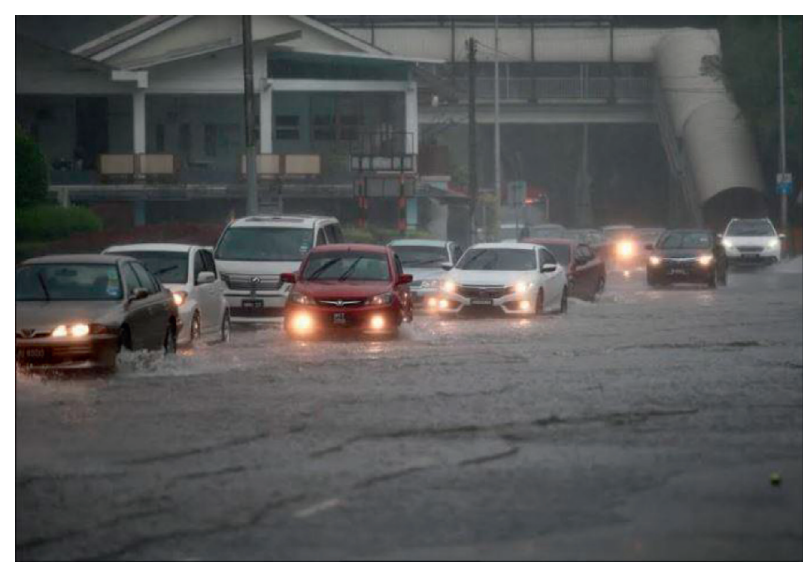

FIgURE 3: Road flood disasters registered in Malaysia.

typically only occur under limited conditions and in certain periods, whereas moisture flow in layers of pavement can occur under unsaturated conditions most of the time. As reflected by [54], the amount of moisture that infiltrates is dependent on the soil matrix's permeability, gravity, and suction. Permeability is a function of the moisture content (or suction of soil) in unsaturated soils where unsaturated properties of drainage regulate moisture flow. However, improving one's comprehension of the movement or flow of moisture in the pavement network is only accomplished through the use of a saturated and unsaturated flow model.

For instance, [55] introduced a three-dimensional flowdependent finite element model (FEM) modelling system of a pavement subsurface drainage system to include the impact of the pavement's longitudinal slope or fall and the reliability of the edge drainage system. The confirmation of both the two- and three-dimensional aspects of the FEM model in addition to the incorporation of field discharge information was exceptional, indicating that the system remained unsaturated even during significant rainfall conditions under the optimal condition of all drainage parts. Similarly, using permeable floodplains is an urban flood mitigation tool [23]. Reference [56] also performed an analysis of global sensitivity and identified high sensitivity of unsaturated material properties, while [57] created a model founded on surrogates for the statistical assessment of leaky or cracked pavements.

Regarding the structural design of the pavement, the integrated climate model (ICM) takes into consideration the influences of both temperature and moisture content $(\mathrm{MC})$ as a climate variable or input. Moreover, quantifying the distribution of the MC over a certain period based on given rainfall distribution (precipitationinfiltration-drainage process) is important for the design of drainage layers in addition to the structural design of payment. Rainfall simulation is a further design aspect that aids in understanding the drainage layer output for a certain volume of inflow. The main precipitation parameters, in particular their intensity and duration, regulate the movement of moisture in the subsurface of the pavement [58]. The efficiency, in this case, is expressed in the saturation level generated through the 
inflow. The lower the saturation level is, the less the pavement material degradation level is; therefore, the lesser the value attributed to the pavement life cycle cost.

The efficiency of the system can be enhanced by constructing the surface of the drainage system to include adequate drainage qualities and geometry in order to allow the system to acquire a lesser degree of saturation during the pavement's service life, including under intense inflow events [58]. The extent of flooding caused by precipitation and other inflows may be determined through modelling both the absorption and the drainage process simultaneously. Once the MC of the drainage layer surpasses the remaining $\mathrm{MC}$, the drainage process begins. Using infiltration, modelling MC produced by the inflow episode can be determined. The inflow level will always be lower than the inundated permeability for drainable systems having adequate penetrability, as the network will become less saturated [27].

\section{Impacts of Drainage Systems Flooding on Road Structure}

Given the liquid contact and the water content of the granular product, it is often recognised that the road pavement's stability is directly related with the street drainage scheme [46]. The key component of road construction, design, and maintenance can simply be defined as drainage [59]. Therefore, road drainage directly affects the street surface and its efficiency. On the other hand, substandard drainage infrastructure, which includes poor construction standards and the use of low-quality materials, will negatively affect the life of the pavement as shown in Figure 4. The findings of this present study show that the quality and sustainability of the drainage system and extent needs to be investigated.

Drainage infrastructure continues to be widely discussed in the field of road engineering that involves several elements related to road and highway effectiveness, including roads, corners, overpasses, and further cross-drainage structures. For example, acquiring a reliable and stable stormwater collection system needs to be articulately designed, especially for distant or remote urbanised and rural areas, which require protection from flooding events. As such, performing an accurate evaluation of potential use of land and recommending appropriate projects to control flooding is essential to sustain road transport networks. In addition, adequate preparation and planning for forthcoming predictions can offer crucial evidence for the design demands. Also, road developers must perform an appropriate evaluation to assess the prospective effects of flooding or other components linked to road maintenance [37].

4.1. Road Stormwater Drainage System Performance. A few scientists have researched the effect of future climate change on road drainage systems and productivity, according to the literature (i.e., intense rainfall and flooding incidents) $[3,22,60]$. Notably, the studies and assessments tend to be premised on future projection models [24, 61-63]. An excellent example demonstrating the importance of assessing road drainage has been undertaken by [64], where the drainage system efficiency in Sweden was verified, evaluated, and scored based on a number of variables and highlighting several issues as illustrated in Figure 5.

In reference to Figure 5, the lowest score of $15 \%$ correlated with the blockage of the drainage inlet and was highlighted as the topmost issue faced by the drainage system in Sweden. In addition, a score of $12 \%$ related to the insufficient capacity of drainage systems in general because of the vast volume of stormwater. Moreover, a score of $11 \%$ related to the inadequate diameter of pipes, which constitutes a special circumstance of "culvert" drainage, impacted by the increase in the volume of the discharge. The case depicted of Sweden indicates the significance of evaluating drainage systems in order to maintain sustainability and to reduce or avert the drainage system from surpassing its functional design.

4.2. Design Requirements for Road Stormwater Drainage Systems. Global warming and rising greenhouse gases have an adverse effect on climate change. Climate change is often perceived in combination with the increased likelihood of significant rainfall events, where more frequent and recurrent flooding is anticipated [65]. Processes have evolved over time in designing drainage systems that are more robust and supporting infrastructure, thereby resulting in a much better comprehension of global warming and climate change. Likewise, the pneumatic design of various types of drainage systems has led towards establishing a unified and viable design technique that allows the detention of more stormwater and affords a useful framework regarding climate change. Consequently, embedded information such as climate projection reliability, drainage infrastructure effectiveness, and lifespan needs to be reviewed, and where needed, modified. In providing the correct crown and longitudinal (fall) slopes, it is necessary to maintain proper road geometry. This reduces the length of the water drainage route that runs through the pavement that prevents the flow of water from building up. Here, a suitable link or the integration between the road network and regular maintenance of drainage systems is needed [66].

In an investigation initiated by [7], they developed a series of standards to avoid expensive reconstruction of drainage systems applying a linear relationship towards "time of return" and "date of return." Further studies to analyse the distribution of rainfall and intense situations covering proper temporal and spatial scales remain feasible. Likewise, research into innovative methods to promote more realistic nonlinear characteristics is critical towards future drainage system design. In the literature, a further issue was discovered relating to the design and planning process [67]. Both elements could be improved by evaluating appropriate rainfall data and statistics concerning the intensity-duration-frequency (IDF) curves. This would help apply proper input information when designing drainage systems. 


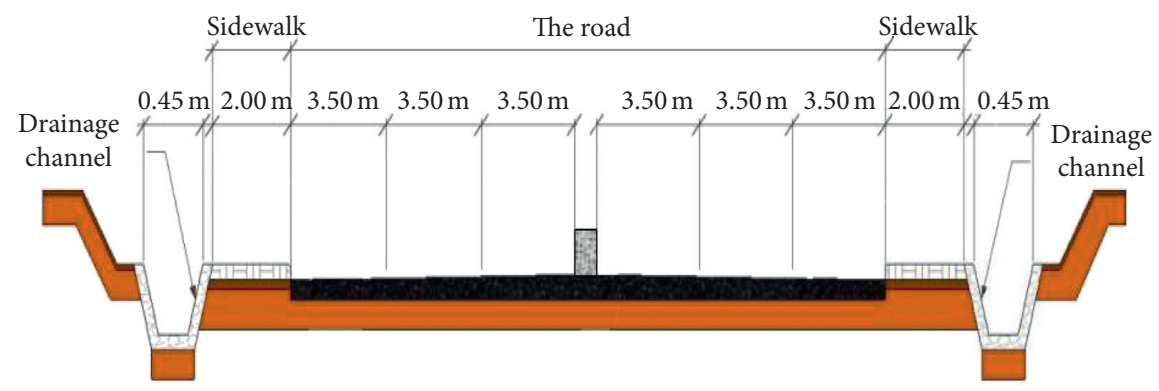

Figure 4: Typical existing condition of highway drainage canal; the design of drainage systems may vary according to the runoff calculation procedures.

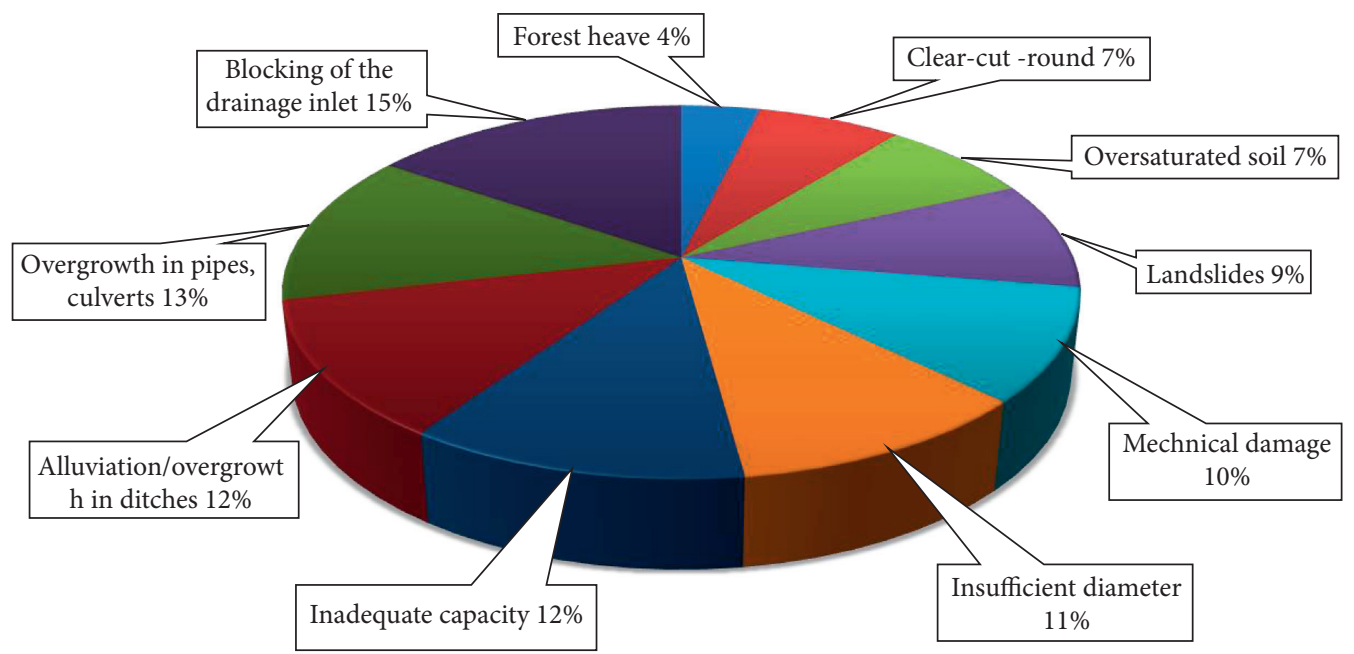

FIGURE 5: Scoring of different factors linked to real road drainage performance (redrawn from [64]).

\section{Hydrological Modelling Studies}

Watershed runoff is an important step towards evaluating and examining the release of water flowing into road drainage systems. Here, hydrological models can be used to offer detailed and comprehensive data about the way the notion of water hydrology can affect the climate [68]. To further understand this notion, the simulation of flood propagation events requires a two-dimensional overflow model to reflect whether the surface runoff water surpasses the diminished capacity of the drainage system [46].

Furthermore, there are a few applications (commercial and open-source software) able to offer accurate findings with respect to runoff generation and street drainage founded on pragmatic and trustworthy sustainability frameworks. These models are used in practice to calculate watershed responses to extreme climate change and the impact of optimum discharges [69]. Additionally, hydrological framework models include a few map-based parameters and databases that include information related to hydrology, geology, and geography. Aside from that, models of numerical simulation can provide relatively uncomplicated methods that afford practical data and information about climate change and the after-effects frequently employed by scientists in undertaking catchment area studies.
The models reflecting rainfall-runoff hydrological watershed generation framework models are commonly accepted for road planning and design. Here, a standard approach (WATBAL), a physically-based distributed system (MIKESHE), and combined theoretical modeling method (NAM) were developed into three separate runoff generation model types and applied to three catchments in Zimbabwe [70]. The researchers asserted that ten models were used in modelling the model drainage systems, namely, WBM, SWMM, StormTac, SLAMM, RUNQUAL, PURRS, P8, MUSIC, and MOUSE (Figure 6). In terms of using the tool in modelling the generated runoff from a watershed, given the reliability of the software, MOUSE was shown to have the highest rating. A detailed evaluation of the models used in the generation and routing of flood drainage by [21] is illustrated in the figure below.

The choice of an acceptable hydrological model is generally based on several principles as presented by [71], namely, model precision and accessibility for distinct spatial and temporal based features, availability of input data, calibrated output, and applicability of the model in different fields. The principles consider multiple elements that constitute a suitable simulation of the produced runoff and are essential in achieving a reliable model. In recent years, street drainage models have given more precise measurements and statistical methods. However, the models represent an estimation of complex events, and 


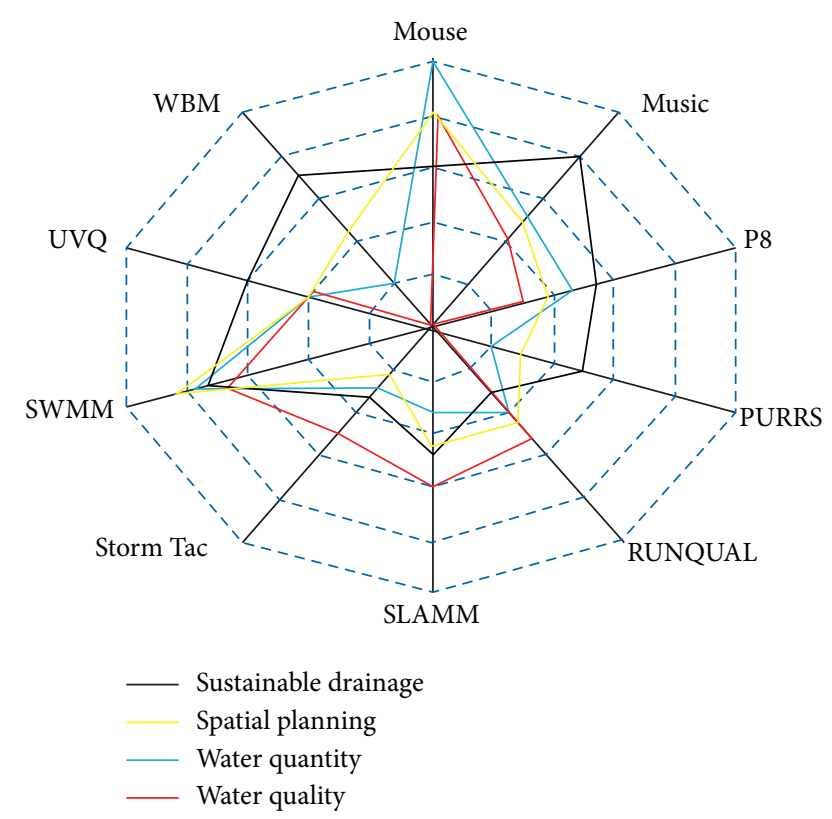

FIgURE 6: Use of several hydrological models for quality and amount of water, spatial planning, and sustainability of drainage (redrawn from [21]).

separating one model from another provides a distinct advantage for modelling runoff [71].

5.1. Watershed Runoff Generation Models. Table 1 describes some of the previous studies of hydrological modelling for assessing drainage performance in different regions.

Advancements in technology over the years have allowed hydrological processes to be modelled more accurately compared with expensive and prolonged field trials. Table 1 presents a summary of the application of different hydrological modeling technology-based mathematical models in which several scholars have developed flexible mathematical models. Such studies have identified the need for an effective drainage system layout to solve drainage problems.

\subsection{Challenges to the Road Stormwater Drainage System.} Previously, structural steps such as the construction of additional drainage systems, including pump stations and storage dams, have been implemented to prevent and alleviate urban flooding. However, these steps are expensive and time-consuming. Therefore, to optimise the effectiveness of flood mitigation, nonstructural steps, such as the efficient operation of drainage facilities, are important [82]. Table 2 presents the techniques utilised to improve the performance of road drainage systems in reducing floods.

The establishment of urban road drainage systems has been constructed to cater for preceding climatic conditions and, as such, may be unable to cater to present or future shifts in rainfall. Therefore, it is important to adapt this infrastructure to climate change and storm events to improve system performance and sustainability. Global warming and climate change present a significant challenge to our future that needs to be addressed, given the adverse effects to our climate and sustainability. Through developing models to assess resilience and improve existing drainage quality and performance, researchers are providing further insight into the techniques used to improve drainage efficiency and minimise the impact of flooding, as depicted in Table 2.

\section{Future Trends}

Form the literature review, it is evident that new approaches need to be developed based on soft computing models, given they will offer practical guidance in evaluating the impacts of climate change going forward, particular regarding road drainage systems (i.e., adaptive responses to preserve road drainage sustainability). Likewise, integrating hydrological models with new or refined processes is crucial in the context of applying it to the broader hydraulic system design, given the benefits of additional, if not rigorous, modelling, in the sense of hydraulic and hydrological advancement. Reference [83] employed the enhanced L-THIA-LID model and reported a reduction in the volume of runoff and pollutants while a hydrologic modelling system based on MIKE-SHE was employed to reproduce surface flow as runoff and was viewed as a viable contribution in terms of subsurface drainage flow channelled via a tiled drainage system [76].

In this study, hydrological modelling employed the Twodimensional, Runoff, Erosion and Export (TREX) method in order to comprehend the Seri Kembangan-based watershed response in Malaysia flooding incidences. The model was selected given its characteristics of a distributed two-dimensional model, and compatibility with ArcGIS, adapting to continuous rainfall modelling. Notably, this model has been thoroughly tested and broadened to cater to distinct watershed sizes, ranging from large to small $[85,86]$. Likewise, the circulated and used two-dimensional TREX system has widely applied in the course of intense precipitation events to simulate erosion, overland flooding, and channel flow. Channel and overland flows are modelled in one and two dimensions, respectively, applying diffusive wave estimation. The TREX hydrological submodel contains four primary processes: (1) interception and precipitation, (2) loss of transmission and infiltration, (3) storage of depression, and (4) channel and overland flow.

Accordingly, developers and decision-makers in road and highway engineering disciplines should determine intense flooding event rates for drainage system infrastructure, given the complexity of this issue and its association to the variety of road segments, namely, bridges, corners, and surface channels. Similarly, consideration should be directed towards carrying out adequate maintenance and designing an optimal discharge layout for other buildings that require such data. To assess and gauge the risks related to drainage capacity, the anticipated optimal values that cause drainage overload and the impact on our road network should be used. A recent study has shown that there are improvements that can be applied to the simulation of hydrologic processes, however; a universally accepted model does not exist at present since each model has its own unique benefits and drawbacks, restrictions, and information needs [66]. 
TABLE 1: Summary of hydrologic modelling studies.

\begin{tabular}{|c|c|c|c|c|}
\hline Source & Objectives & Region & Methodology & Findings \\
\hline [72] & $\begin{array}{l}\text { Assessed the predictions of } \\
\text { regular streamflow by applying } \\
\text { two basic theoretical models and } \\
\text { one complex model to four major } \\
\text { watercourses }\end{array}$ & $\begin{array}{l}\text { Blue Nile flow at the } \\
\text { Ethiopian-Sudanese } \\
\text { border }\end{array}$ & $\begin{array}{l}\text { Rainfall-runoff models, GR4 J, } \\
\text { IHACRES, and SWAT were } \\
\text { chosen to evaluate the } \\
\text { hydrological processes }\end{array}$ & $\begin{array}{l}\text { The GR4 J model produced the best } \\
\text { results for the Ribb watershed, the } \\
\text { SWAT model for the Gilgel Abay } \\
\text { watershed, and the IHACRES model } \\
\text { for the Gummera and Megech } \\
\text { watersheds }\end{array}$ \\
\hline [73] & $\begin{array}{l}\text { Determined the parametric } \\
\text { uncertainty in hydrological } \\
\text { modelling using generalised } \\
\text { likelihood uncertainty estimation } \\
\text { (GLUE) }\end{array}$ & $\begin{array}{l}\text { Kootenay watershed, } \\
\text { Canada }\end{array}$ & $\begin{array}{l}\text { The hydrological model } \\
\text { employed in this study was the } \\
\text { simple LUmped reservoir } \\
\text { parametric (SLURP) model }\end{array}$ & $\begin{array}{l}\text { The model predicted the outflows } \\
\text { with reasonable accuracy and hence } \\
\text { could be used for future modelling of } \\
\text { similar watersheds }\end{array}$ \\
\hline$[74]$ & $\begin{array}{l}\text { Variable infiltration capacity } \\
\text { model (VIC), TOPMODEL, } \\
\text { HBV, MIKESHE, and soil and } \\
\text { water assessment tool (SWAT) } \\
\text { model }\end{array}$ & - & Use of exis & $\begin{array}{l}\text { SWAT model requires just a little } \\
\text { direct calibration to achieve } \\
\text { satisfactory hydrological projections }\end{array}$ \\
\hline [75] & $\begin{array}{l}\text { Assessment of the impact of } \\
\text { climate change on the } \\
\text { hydrological regime of the } \\
\text { Paraguaçu River Basin }\end{array}$ & $\begin{array}{l}\text { Paraguaçu River } \\
\text { Basin, northeastern } \\
\text { Brazil }\end{array}$ & $\begin{array}{l}\text { Hydrological impact } \\
\text { simulations were conducted } \\
\text { using the soil and water } \\
\text { assessment tool (SWAT) for } \\
\text { 2020-2040 }\end{array}$ & $\begin{array}{l}\text { The bias correction algorithm plays a } \\
\text { significant role when assessing } \\
\text { climate model estimates and their } \\
\text { applicability to hydrological } \\
\text { modelling }\end{array}$ \\
\hline$[76]$ & $\begin{array}{c}\text { MIKE SHE, a hydrological } \\
\text { modelling system, was used to } \\
\text { simulate surface flow as runoff } \\
\text { and underground drainage via } \\
\text { infrastructure for draining } \\
\text { surfaces }\end{array}$ & Argesel River & $\begin{array}{l}\text { MIKE SHE modelling system } \\
\text { was used }\end{array}$ & $\begin{array}{l}\text { The soil type has an effect on the } \\
\text { functions of infiltration/ } \\
\text { evapotranspiration and recharge, and } \\
\text { the matrix of hydraulic conductivity } \\
\text { is the dominant parameter at the } \\
\text { saturated zone level }\end{array}$ \\
\hline
\end{tabular}

Evaluation of the capability of the

hydrological model catchment simulation (CSIM) to

[77] characterize the seasonal and regional differences in river discharge
Baltic sea drainage Spatiotemporal bias was used in basin (BSDB) the allocation of monthly modelling errors over the BSDB
The CSIM model reproduced the yearly flows over the BSDB with precision
France, the United

[78]

Examine the role of hydrological States, Australia, the models in complexity
Ivory Coast, and Brazil
A detailed comparative performance assessment of 19 daily lumped models systems was performed on 429 catchments
Review of strengths, weaknesses, opportunities, and threats

[79]

(SWOT) analysis of models of soil water flow
- $\quad$ Use of existing literatures
If models become more user-friendly (or tolerant) and perceive heterogeneity, the likelihood that they will be adopted by the wider model user community will increase

DRAINMOD is a process based model, distributed on a field scale that

can explain poorly drained and artificially drained soil hydrology

The SWAT model gets well observed flow with a Nash-Sutcliffe efficiency

(NSE) exceeding 0.74 and PBIAS exceeding $10 \%$ for the period of the calibration and verification 
TABLE 2: Techniques to optimise the performance of road stormwater drainage system.

\begin{tabular}{|c|c|c|c|}
\hline Source & Objectives & Techniques & Findings \\
\hline [25] & $\begin{array}{l}\text { Hydrological model definition, } \\
\text { development scenarios, and flood } \\
\text { mitigation prediction processes }\end{array}$ & $\begin{array}{l}\text { The US EPA stormwater management } \\
\text { model (SWMM) was used to test the } \\
\text { flood prevention impact of LID }\end{array}$ & $\begin{array}{l}\text { LID models need to be paired with } \\
\text { traditional flood control measures to } \\
\text { alleviate the risks posed by urban flooding } \\
\text { resulting from more substantive and } \\
\text { prolonged storms }\end{array}$ \\
\hline$[82]$ & $\begin{array}{l}\text { Design of an optimisation-based approach } \\
\text { to efficient operational policies in urban } \\
\text { drainage pump stations, considering the } \\
\text { stochastic complexity of rainfall events }\end{array}$ & $\begin{array}{l}\text { The robust rule curve is built based on a } \\
\text { significant number of synthetic rainfall } \\
\text { events resulting from a Monte Carlo } \\
\text { (MC) procedure }\end{array}$ & $\begin{array}{l}\text { Developing an approach to automate the } \\
\text { design of an effective protocol for the } \\
\text { application of pump stations in urban } \\
\text { drainage systems }\end{array}$ \\
\hline$[45]$ & $\begin{array}{l}\text { Proposal for a new collective public } \\
\text { drainage system service scheme }\end{array}$ & $\begin{array}{l}\text { Use of the resilience index to quantify } \\
\text { how well each method of operation } \\
\text { mitigates the extent of the drainage } \\
\text { system failure (i.e., flooding) }\end{array}$ & $\begin{array}{l}\text { For collaborative activities, flood } \\
\text { prevention and adaptation are better than } \\
\text { the current process }\end{array}$ \\
\hline$[83]$ & $\begin{array}{l}\text { Enhanced approaches to long term } \\
\text { assessing hydrological impacts-LID (L- } \\
\text { THIA-LID), improved with further } \\
\text { activities of BMPs and LID }\end{array}$ & $\begin{array}{l}\text { In order to improve the L-THIA-LID } \\
\text { design, data from the BMP database for } \\
\text { global stormwater was used }\end{array}$ & $\begin{array}{l}\text { Reductions in volume of runoff and } \\
\text { pollution levels are equivalent to the } \\
\text { observed impacts of these activities after } \\
\text { introducing BMPs and LID procedures, } \\
\text { both individually and in sequence }\end{array}$ \\
\hline$[84]$ & $\begin{array}{c}\text { Clarify the identification of flood risk } \\
\text { trends through the implementation of } \\
\text { chemical and statistical process control } \\
\text { (SPC) techniques in the Muda River Basin, } \\
\text { Malaysia }\end{array}$ & $\begin{array}{l}\text { Employed principal component analysis } \\
\text { (PCA) technique }\end{array}$ & $\begin{array}{l}\text { Changes in the shape of water levels that } \\
\text { require flood warnings to improve the } \\
\text { existing system used by DID to manage } \\
\text { flood control for Malaysia }\end{array}$ \\
\hline$[60]$ & $\begin{array}{l}\text { Hydrological and hydraulic processes in the } \\
\text { Paranoa Lake basin urban catchment using } \\
\text { the SWMM template }\end{array}$ & $\begin{array}{c}\text { Evaluating the simulation of various } \\
\text { federal district areas, like the Riacho } \\
\text { Fundo Basin }\end{array}$ & $\begin{array}{l}\text { The simulations demonstrated the } \\
\text { calibrated performance and flexibility }\end{array}$ \\
\hline
\end{tabular}

Moreover, the weakness of road drainage systems needs to be articulated, graded, and prioritised as part of routine maintenance programmes. Where remedial works are carried out on street pavements, likewise, any surface drainage problems must be resolved before or in tandem along with research on pavement improvements.

Notwithstanding, the performance of large, distributed drainage networks must be well understood, and where possible and feasible, wide-ranging schemes should be explored to mitigate against the risk of floods due to global warming and climate change. Even though fully distributed hydrodynamic models have been introduced in a limited number of studies, the computational complexity that has been reviewed in this study could, therefore, be applied to many possible configurations [78].

\section{Conclusion}

Coping with disastrous events, each country tends to have its recovery plan. Similarly, Malaysia has developed various approaches that can be used holistically to provide predisaster data and assistance due to flooding in areas that are prone to flooding. However, the country needs to enhance its predisaster delivery system to avert future consequences from flood damage due to global warming and climate change. Flooding events that occur during a crisis need effective communication and collaboration among the various group and parties that exist in the flood plain. For example, coordinating at a district level needs to be efficient and practical in protecting and rescuing those affected and lowering the loss to properties. This study is significant since it aids in defining the characteristics associated with overflow and distinct flood locations. As such, this will enable the development of certain strategies and plans for designing, constructing and maintaining roads in those affected regions.

The extent of increasing rainfall and the escalation of global warming undoubtedly cause severe environmental issues, namely, the release of stormwater, surface-water runoff. and floods. Such issues relate directly and indirectly to the design of drainage management schemes, as drainage systems historically were designed based on a given rainfall cycle or pattern. Therefore, resolving uncertainty and variability with respect to climate change is important, if not vital, to enhance the reliability and sustainability towards existing drainage systems. However, even though developments in drainage systems and design have improved over recent decades employing new and contemporary techniques, the functionality of the system afforded disadvantages as well. Likewise, floods have exacerbated the problems and needs for road drainage systems, water quality, runoff, and damage to property resulting in economic losses.

As such, road authorities and local districts need to provide sufficient funds for road drainage maintenance, infrastructure enhancement work, bridges, and culvert maintenance work. These should also be targeted towards employing drainage inspectors to monitor, track, and report on maintenance work. Additionally, a maintenance 
programme is essential to sustain the surface drainage system. Using resources (human and machinery) can assist in maintaining drains and culverts, as it is necessary to clean and maintain existing drain inlets and outlets. Likewise, computer software design for planning, assessing, and designing such systems in addition to managing urban road surface drainage systems, including regulating drainage infrastructures, is needed. Not forgetting, hydrologists and decision-makers need to be involved in all discussions and issues that are raised.

One of the biggest concerns is regarding the limited knowledge surrounding natural phenomena, triggered by global warming and climate change. Effort must be directed towards obtaining accurate hydrological modelling to minimise or avert damage to drainage systems to accommodate peak flow frequency and duration. Moreover, reliable hydrographic information is equally important to model road drainage network layouts and to predict the impact of climate change to ensure safe and effective drainage systems. Lastly, this study examined several recent models that have been developed for advanced drainage systems and waterways that are designed and planned around the impact of climate change.

\section{Data Availability}

The data used to support the findings of this study are available from the corresponding author upon request.

\section{Conflicts of Interest}

The authors declare that they have no conflicts of interest.

\section{Acknowledgments}

The authors would like to express their gratitude to the Malaysian Highway Authority (LLM), for providing the annual flood reports for Seri Kembangan Expressway and the financial support by the National Universiti Kebangsaan Malaysia (UKM). Furthermore, thanks are due to the financial support by the Libyan Ministry of Education under their scholarship program for $\mathrm{PhD}$ studies of the first author.

\section{References}

[1] S. Solomon, D. Qin, and M. Manning, Climate Change 2007: The Physical Science Basic, Contribution of Working Group I to the Fourth Assessment Report of the Intergovernmental Panel on Climate Change, Intergovernmental Panel on Climate Change, Geneva, Switzerland, 2007.

[2] Z. Kalantari, A. Briel, S. W. Lyon, B. Olofsson, and L. Folkeson, "On the utilization of hydrological modelling for road drainage design under climate and land use change," Science of the Total Environment, vol. 475, pp. 97-103, 2014.

[3] Q. Zhou, "A review of sustainable urban drainage systems considering the climate change and urbanization impacts," Water, vol. 6, no. 4, pp. 976-992, 2014.

[4] F. W. Zwiers and V. V. Kharin, "Changes in the extremes of the climate simulated by CCC GCM2 under $\mathrm{CO}_{2}$ Doubling," Journal of Climate, vol. 11, no. 9, pp. 2200-2222, 1998.
[5] M. Z. Hashmi, A. Y. Shamseldin, and B. W. Melville, "Downscaling of future rainfall extreme events: a weather generator based approach," in Proceedings of the the 18th World IMACS Congress and MODSIM09 International Congress on Modelling and Simulation. Cairns, Australia, Melbourne, VIC, Australia, July 2009.

[6] Q. Zhou, G. Leng, J. Su, and Y. Ren, "Comparison of urbanization and climate change impacts on urban flood volumes: importance of urban planning and drainage adaptation," Science of The Total Environment, vol. 658, pp. 24-33, 2019.

[7] A. Mailhot and S. Duchesne, "Design criteria of urban drainage infrastructures under climate change," Journal of Water Resources Planning and Management, vol. 136, no. 2, pp. 201-208, 2010.

[8] R. L. Copstead and D. K. Johansen, Water/Road Interaction: Examples from Three Flood Assessment Sites in Western Oregon, US Department of Agriculture, Forest Service, Washington, DC, USA, 1998.

[9] L. N. Ireri, An Investigation into Suitability of Storm Water Drainage Systems in Nairobi's CBD, Bachelor of Building Economics, University of Nairobi, Nairobi, Kenya, 2009.

[10] L. Moretti and G. Loprencipe, "Climate change and transport infrastructures: state of the art," Sustain, vol. 10, 2018.

[11] L. Pinter, L. Bizikova, K. Kutics, and A. Vari, "Developing a system of sustainability indicators for the Lake Balaton region,” Tájökológiai Lapok, vol. 6, pp. 271-293, 2008.

[12] M. S. N. Ismail and A. N. A. Ghani, "An overview of road damages due to flooding: case study in Kedah state, Malaysia," in Proceedings of the AIP Conference Proceedings 1892, Penang, Malaysia, October 2017.

[13] M. M. A. Khan, N. A. B. Shaari, A. M. A. Bahar, M. A. Baten, and D. A. Bin Nazaruddin, "“Flood impact assessment in Kota Bharu, Malaysia: a statistical analysis," World Applied Science Journal, vol. 32, pp. 626-634, 2014.

[14] S. M. H. Shah, Z. Mustaffa, and K. W. Yusof, "Disasters worldwide and floods in the Malaysian region: a brief review," Indian Journal of Science and Technology, vol. 10, 2017.

[15] M. S. N. Ismail, A. N. A. Ghani, and Z. M. Ghazaly, "The characteristics of road inundation during flooding events in peninsular Malaysia," International Journal of GEOMATE, vol. 16, pp. 129-133, 2019.

[16] W. H. M. Wan Mohtar, J. Abdullah, K. N. Abdul Maulud, and N. S. Muhammad, "Urban flash flood index based on historical rainfall events," Sustainable Cities and Society, vol. 56, 2020.

[17] A. H. Syafrina, M. D. Zalina, and A. Norzaida, "Climate projections of future extreme events in Malaysia," American Journal of Applied Sciences, vol. 14, no. 3, pp. 392-405, 2017.

[18] M. Hossain and C. Davies, "A GIS to reduce flood impact on road transportation systems," in Proceedings of the ESRI International User Conference, pp. 1-11, San Diego, CA, USA, August 2004.

[19] E. Torabi, To Be beside the Seaside: Urban Resilience to Climate-Related Disasters in Coastal Cities, Commonwealth Scientific and Industrial Research Organisation, Australia, 2017.

[20] Z. Yazdanfar and A. Sharma, "Urban drainage system planning and design-challenges with climate change and urbanization: a review," Water Science and Technology, vol. 72, no. 2, pp. 165-179, 2015.

[21] A. Elliott and S. Trowsdale, "A review of models for low impact urban stormwater drainage," Environmental Modelling \& Software, vol. 22, no. 3, pp. 394-405, 2007. 
[22] E. Goore Bi, P. Gachon, M. Vrac, and F. Monette, "Which downscaled rainfall data for climate change impact studies in urban areas? Review of current approaches and trends," Journal of Theoretical Applied Climatology, 2015.

[23] B. Hewitson, K. Waagsaether, J. Wohland, K. Kloppers, and T. Kara, "Climate information websites: an evolving landscape," Wiley Interdisciplinary Reviews: Climate Change, vol. 8, pp. 1-22, 2017.

[24] S. Hallegatte, N. Ranger, O. Mestre et al., "Assessing climate change impacts, sea level rise and storm surge risk in port cities: a case study on Copenhagen," Climatic Change, vol. 104, no. 1, pp. 113-137, 2011.

[25] H.-P. Qin, Z.-X. Li, and G. Fu, "The effects of low impact development on urban flooding under different rainfall characteristics," Journal of Environmental Management, vol. 129, pp. 577-585, 2013.

[26] H. Arisz and B. Burrell, "Urban drainage infrastructure planning and design considering climate change," in Proceedings of the 2006 IEEE EIC Climate Change Conference, Ottawa, ON, Canada, May 2006.

[27] H. Nissan, L. Goddard, E. C. de Perez et al., "On the use and misuse of climate change projections in international development," Wiley Interdisciplinary Reviews: Climate Change, vol. 10, pp. 1-16, 2019.

[28] M. Sakradzija and D. Klocke, "Physically constrained stochastic shallow convection in realistic kilometer-scale simulations," Journal of Advances in Modelling Earth Systems, vol. 10, no. 11, pp. 2755-2776, 2018.

[29] A. W. Wood, L. R. Leung, V. Sridhar, and D. P. Lettenmaier, "Hydrologic implications of dynamical and statistical approaches to downscaling climate model outputs," Climatic Change, vol. 62, no. 1-3, pp. 189-216, 2004.

[30] B. C. Hewitson, J. Daron, R. G. Crane, M. F. Zermoglio, and C. Jack, "Interrogating empirical-statistical downscaling," Climatic Change, vol. 122, no. 4, pp. 539-554, 2014.

[31] IPCC-TGICA, "General guidelines on the use of scenario data for climate impact and adaptation assessment," Finnish Environment Institute, vol. 312, p. 66, 2007.

[32] R. Kabiri, V. Ramani Bai, and A. Chan, "Assessment of hydrologic impacts of climate change on the runoff trend in Klang Watershed, Malaysia," Environment Earth Science, vol. 73, pp. 27-37, 2014.

[33] T. Yang, H. Li, W. Wang, C. Xu, and Z. Yu, "Statistical downscaling of extreme daily precipitation, evaporation, and temperature and construction of future scenarios," Hydrological Processes, 2011.

[34] M. Devak, C. T. Dhanya, and A. K. Gosain, "Dynamic coupling of support vector machine and K-nearest neighbour for downscaling daily rainfall," Journal Hydrology, vol. 525, pp. 286-301, 2015.

[35] B. Ibrahim, H. Karambiri, and J. Polcher, "Hydrological impacts of the changes in simulated rainfall fields on nakanbe basin in Burkina Faso," Climate, vol. 3, pp. 442-458, 2015.

[36] Y. Tramblay, W. Badi, F. Driouech, S. El Adlouni, L. Neppel, and E. Servat, "Climate change impacts on extreme precipitation in Morocco," Global and Planetary Change, vol. 82-83, pp. 104-114, 2012.

[37] S. G. D/iya, M. B. Gasim, M. E. Toriman, and M. G. Abdullahi, "Floods in Malaysia: historical reviews, causes, effects and mtigations approach," International Journal of Interdisciplinary Research and Innovation, vol. 2, pp. 59-65, 2014.

[38] G. Ziervogel and A. Taylor, "Climate change adaptation and international development," 2010.
[39] T. Parzybok, B. Clarke, and D. M. Hultstrand, "Average recurrence interval of extreme rainfall in real-time," 2011.

[40] Y. Zhou, W. K. M. Lau, and G. J. Huffman, "Mapping TRMM TMPA into average recurrence interval for monitoring extreme precipitation events," Journal of Applied Meteorology and Climatology, vol. 54, no. 5, pp. 979-995, 2015.

[41] B. C. Burrel, K. Davar, and R. Hughes, "review of flood management considering the impacts of climate change," Water International, vol. 32, no. 3, pp. 342-359, 2007.

[42] R. M. Davar, D. J. Balmforth, A. J. Saul, and J. D. Blanskby, "Flooding in the future - predicting climate change, risks and responses in urban areas," Water Science and Technology, vol. 52, no. 5, pp. 265-273, 2005.

[43] N. Weng Chan, "Impacts of disasters and disasters risk management in Malaysia: the case of floods impacts of disasters and disaster risk management in Malaysia: the case of floods," ERIA Research Project Report, pp. 503-551, 2012.

[44] N. W. Chan, "Impacts of disasters and disaster risk management in Malaysia: the case of floods," Springer, Berlin, Germany, 2015.

[45] K. J. Lee, A Case Study of Collaborative Disaster Management in Malaysia, University of Canterbury, Christchurch, New Zealand, 2016.

[46] H.-K. Chang, Y.-C. Tan, J.-S. Lai, T.-Y. Pan, T.-M. Liu, and C.-P. Tung, "Improvement of a drainage system for flood management with assessment of the potential effects of climate change," Hydrological Sciences Journal, vol. 58, no. 8, pp. 1581-1597, 2013.

[47] H. Keizrul Bin Abdullah, "Integrated river basin management," Rivers: Towards Sustainable Development, vol. 3-14, 2002.

[48] H. Ahmad, "Flood and Drought Management in Malaysia," in Proceedings of the Flood and drought management in Malaysia, Malaysia, Kuala Lumpur, June 2007.

[49] M. K. Negara, "Laporan Kesiapsiagaan Bencana Semasa Monsun Timur Laut Malaysia," 2011.

[50] M. A. Rahman, "Pengujian Pengaplikasian Sistem Pengurusan Sistem Pengurusan Banjir Bersepadu Dalam Analisis Limpahan Banjir," in Malaysia Geospatial ForumInternational Water Association, London, UK, 2012.

[51] NDMO and National Disaster Management Organisation, "Brief note on the roles of the national security Council, Prime minister's department as national disaster management organisation (NDMO)," Disaster Management Division National Security Council Prime Minister's Department, vol. 13, 2011.

[52] UNISDR, Malaysia Disaster \& Risk Profile. Basic Country Statistics and Indicators. Prevention Web. Electronic Source, UNISDR, London, UK, 2014.

[53] P. Ariza and B. Birgisson, "Evaluation of water flow though pavement systems," Journal of Chemical Information and Modeling, vol. 53, 2002.

[54] J. R. Philip, Theory of Infiltration, Elsevier, Amsterdam, Netherlands, 1969.

[55] Y. Liu, "Three dimensional finite element modeling of pavement subsurface drainage systems," Doctoral Dissertation, University of Kentucky, Lexington, KY, USA, 2005.

[56] M. Turco, G. Brunetti, M. Porti, G. Grossi, M. Maiolo, and P. Piro, Metals Potential Removal Efficiency of Permeable Pavement, Springer, Berlin, Germany, 2018.

[57] S. Peruccacci, M. T. Brunetti, S. L. Gariano, M. Melillo, M. Rossi, and F. Guzzetti, "Rainfall Thresholds for Possible Landslide Occurrence in Italy," Geomorphology, vol. 290, pp. 39-57, 2017. 
[58] S. A. Kalore, G. L. Sivakumar Babu, and R. B. Mallick, "Design approach for drainage layer in pavement subsurface drainage system considering unsaturated characteristics," Transportation Geotechnics, vol. 18, pp. 57-71, 2019.

[59] A. Dawson, "Water in road structures: movement, drainage and effects," Geotechnical, Geological and Earthquake Engineering, vol. 5, 2009.

[60] F. P. Souza, M. E. L. Costa, and S. Koide, "Hydrological Modelling and Evaluation of Detention Ponds to Improve Urban Drainage System and Water Quality," Water (Switzerland), vol. 11, pp. 1-17, 2019.

[61] N. Ranger, S. Hallegatte, S. Bhattacharya et al., "An assessment of the potential impact of climate change on flood risk in Mumbai," Climatic Change, vol. 104, no. 1, pp. 139-167, 2011.

[62] P. Kirshen, L. Caputo, R. Vogel, P. Mathisen, A. Rosner, and T. Renaud, "Adapting urban infrastructure to climate change: a drainage case study," Journal of Water Resources Planning and Management, vol. 2014, pp. 1-11, 2014.

[63] M. Shahabul Alam and A. Elshorbagy, "Quantification of the climate change-induced variations in Intensity-DurationFrequency curves in the Canadian Prairies," Journal of $\mathrm{Hy}$ drology, vol. 527, pp. 990-1005, 2015.

[64] Z. Kalantari and L. Folkeson, "Road drainage in Sweden: current practice and suggestions for adaptation to climate change," Journal of Infrastructure System, vol. 19, 2012.

[65] K. E. Trenberth, "Conceptual framework for changes of extremes of the hydrological cycle with climate change," Climatic Change, vol. 42, no. 1, pp. 327-339, 1999.

[66] A. Singh, "Environmental problems of salinization and poor drainage in irrigated areas: management through the mathematical models," Journal of Cleaner Production, vol. 206, pp. $572-579,2019$.

[67] B. M. McEnroe and C. B. Young, "Calibration of storm drainage design inputs for a small urban watershed," in Proceedings of the World Environment Water Resource Congress New Mexico USA, Albuquerque, NM, USA, May 2012.

[68] L. Li, J. Xia, C.-Y. Xu, and V. P. Singh, "Evaluation of the subjective factors of the GLUE method and comparison with the formal Bayesian method in uncertainty assessment of hydrological models," Journal of Hydrology, vol. 390, no. 3-4, pp. 210-221, 2010.

[69] M. Ostwald and D. Chen, "Land-use Change: Impacts of Climate Variations and Policies Among Small-Scale Farmers in the Loess Plateau, China," Land Use Policy, vol. 23, pp. 361-371, 2006.

[70] J. C. Refsgaard and J. Knudsen, "Operational validation and intercomparison of different types of hydrological models," Water Resources Research, vol. 32, no. 7, pp. 2189-2202, 1996.

[71] Z. Kalantari, P.-E. Jansson, J. Stolte, L. Folkeson, H. K. French, and M. Sassner, "Usefulness of four hydrological models in simulating high-resolution discharge dynamics of a catchment adjacent to a road," Hydrology and Earth System Sciences Discussions, vol. 9, no. 4, pp. 5121-5165, 2012.

[72] G. Tegegne, D. K. Park, and Y. O. Kim, "Comparison of hydrological models for the assessment of water resources in a data-scarce region, the Upper Blue Nile River Basin," Journal of Hydrology: Regional Studies, vol. 14, pp. 49-66, 2017.

[73] P. Vallam, X. S. Qin, and J. J. Yu, "Uncertainty quantification of hydrologic Model," APCBEE Procedia, vol. 10, pp. 219-223, 2014.

[74] G. K. Devia, B. P. Ganasri, and G. S. Dwarakish, "A review on hydrological models," Aquatic procedia, vol. 4, pp. 1001-1007, 2015.
[75] C. A. S. Santos, F. A. Rocha, T. B. Ramos et al., "Using a hydrologic model to assess the performance of regional climate models in a semi-arid watershed in Brazil," Water, vol. 11, no. 1, pp. 1-17, 2019.

[76] J. Yazdi, H. S. Choi, and J. H. Kim, "A methodology for optimal operation of pumping stations in urban drainage systems," Journal of Hydro-Environment Research, vol. 11, pp. 101-112, 2015.

[77] S. W. Lyon, R. Meidani, Y. van der Velde et al., "Seasonal and regional patterns in performance for a Baltic Sea Drainage Basin hydrologic model," Journal of the American Water Resources Association, vol. 51, no. 2, pp. 550-566, 2015.

[78] M. L. Velleux, J. F. England, and P. Y. Julien, "TREX: spatially distributed model to assess watershed contaminant transport and fate," Science of The Total Environment, vol. 404, no. 1, pp. 113-128, 2008.

[79] W. G. M. Bastiaanssen, R. G. Allen, P. Droogers, G. D’Urso, and P. Steduto, "Twenty-five years modeling irrigated and drained soils: State of the art," Agricultural Water Management, vol. 92, no. 3, pp. 111-125, 2007.

[80] R. W. Skaggs, M. A. Youssef, and G. M. Chescheir, "DRAINMOD: model use, calibration, and validation," Transactions of the ASABE, vol. 55, no. 4, pp. 1509-1522, 2012.

[81] A. W. Worqlul, E. K. Ayana, H. Yen et al., "Evaluating hydrologic responses to soil characteristics using SWAT model in a paired-watersheds in the Upper Blue Nile Basin," Catena, vol. 163, pp. 332-341, 2018.

[82] M.-A. Sandu and A. Virsta, "Applicability of mike she to simulate hydrology in argesel river catchment," Agriculture and Agricultural Science Procedia, vol. 6, pp. 517-524, 2015.

[83] C. Perrin, C. Michel, and V. Andréassian, "Does a large number of parameters enhance model performance? Comparative assessment of common catchment model structures on 429 catchments," Journal of Hydrology, vol. 242, no. 3-4, pp. $275-301,2001$.

[84] S. M. Saudi, I. S. D. Ridzuan, A. Balakrishnan, A. Azid, D. M. A. Shukor, and Z. I. Rizman, "New flood risk index in tropical area generated by using SPC technique," Journal of Fundamental and Applied Sciences, vol. 9, no. 4S, p. 828, 2017.

[85] Y. Liu, L. M. Ahiablame, V. F. Bralts, and B. A. Engel, "Enhancing a rainfall-runoff model to assess the impacts of BMPs and LID practices on storm runoff," Journal of Environmental Management, vol. 147, pp. 12-23, 2015.

[86] J. F. England, M. L. Velleux, and P. Y. Julien, "Two-dimensional simulations of extreme floods on a large watershed," Journal of Hydrology, vol. 347, no. 1-2, pp. 229-241, 2007. 